\title{
Manufacturing Profit Maximization under Time-Varying Electricity and Labor Pricing
}

\section{Original Paper ID: CAIE-D-16-01166.}

Major revisions have been highlightedin RED text for your convenience. The answers to reviewers in details were submitted as well.

\begin{abstract}
Profit maximization focuses on maximizing the difference between the revenue and the cost. Two of major cost components in manufacturing are the electricity and labor costs. New electricity tariffs charge manufacturing firms based on time-of-use and critical-peak prices. Some recent research activities have been conducted under such a time-varying framework. However, these studies mainly focus on reducing the electricity cost by shifting production from the onpeak to the off-peak period, and it may not always be consistent with the ultimate goal of profit maximization. This is because employees in various manufacturing industries are entitled a shift differential in their wage profiles. Therefore, this paper addresses how to properly arrange production that leads to the best tradeoff under time-varying pricing of both costs. The production function, the electricity cost model, and the labor cost model are established to formulate the manufacturing profit maximization problem. The effects of the seasons, number of workers, buffer capacity, machine reliability, initial condition, and time-varying pricing on the final solutionsare examined.
\end{abstract}

Keywords: Electricity cost; labor cost; particle swarm optimization; profit maximization; shift differential

\begin{tabular}{|c|c|c|c|}
\hline \multicolumn{2}{|c|}{ Notation } & $H$ & planning horizon (in hours) \\
\hline the ith buffer & b. $\quad$ the ith buffer & $h_{i}$ & the number of parts in $b_{i}$ \\
\hline$B L_{i}$ & blockage probability of $m_{i}$ & $i, j, t$ & indexes \\
\hline \multirow[t]{2}{*}{$B S_{i}$} & simultaneous blockage and & $I D_{i}$ & idle probability of $m_{i}$ \\
\hline & $\begin{array}{l}\text { starvation probability of } m_{i} \\
\text { demand price }\end{array}$ & $\begin{array}{l}m_{i} \\
m \cdot \mathrm{bl}\}\end{array}$ & the ith machine \\
\hline$C_{D T}$ & electricity demand cost & $\left\{m_{i} \mathrm{dn}\right\}$ & the event that $m_{i}$ is down \\
\hline$C_{E N R G T}$ & energy cost & $\left\{m_{i} \mathrm{npr}\right\}$ & the event that $m_{i}$ is not producing \\
\hline \multirow{2}{*}{$\begin{array}{l}C_{E T} \\
C_{L}\end{array}$} & total electricity cost & $\left\{m_{i} \mathrm{st}\right\}$ & the event that $m_{i}$ is starved \\
\hline & labor price & $\left\{m_{i}\right.$ up $\}$ & the event that $m_{i}$ is up \\
\hline$C_{L T}$ & total labor cost & $N$ & number of machines \\
\hline \multirow{2}{*}{$\begin{array}{l}c_{O T} \\
d_{T}\end{array}$} & other fixed cost & $N_{P}$ & number of particles \\
\hline & peak demand & $N_{T}$ & number of PSO iterations \\
\hline$C_{i}$ & capacity of buffer $b_{i}$ & $p_{i}$ & up probability of $m_{i}$ \\
\hline \multirow{2}{*}{$\begin{array}{l}C_{M T} \\
C P_{0}\end{array}$} & material cost & $P R_{i}$ & production rate of $m_{i}$ \\
\hline & production target & $q_{i, j}$ & probability of $b_{i}$ in state $j$ \\
\hline \multirow{2}{*}{$\begin{array}{l}C P_{T} \\
d_{i}, d_{S Y}\end{array}$} & cumulative production level & $r_{1}, r_{2}$ & material and product price \\
\hline & $d_{B L D}, d_{P L A N T}$ electric demand & $S_{i}$ & control signal \\
\hline \multicolumn{2}{|c|}{$d_{i, 2}, d_{i, 1}, d_{i, 0} \quad$ ele } & $S T_{i}$ & starvation probability of $m_{i}$ \\
\hline \multicolumn{2}{|c|}{$D N_{i} \quad$ down probability of $m_{i}$} & $T$ & time slots \\
\hline \multicolumn{2}{|c|}{$e_{i}, e_{S Y S}, e_{B L D}, e_{P L A N T} \quad$ electric energy } & $t_{C}$ & machine cycle time \\
\hline \multicolumn{2}{|c|}{$e_{i, 2}, e_{i, 1}, e_{i, 0} \quad$ electric energy levels } & $t_{D}$ & peak demand measurement interval \\
\hline
\end{tabular}


$t_{i, \text { start }}, t_{i, \text { end }}, t_{i, d u r} \quad$ start/end time and duration

w number of workers

$\boldsymbol{S} \quad$ velocity matrix

$\mathrm{T} \quad$ position matrix
$\mathrm{T}_{G B} \quad$ global best

$\mathrm{T}_{P B} \quad$ personal best

$\theta_{0}, \theta_{1}, \theta_{2} \quad$ PSO coefficients

\section{Introduction}

Profit maximization is a common goal of manufacturing firmsand it is hot research area in the literature (Kalir and Arzi, 1997; Kumar and Chatterjee, 2015; Trigos and López, 2016). It is the process of determining the sales price and fine-tuning the production level to obtain the highest profit (Beattie et al., 2009; Hackman, 2008). The profit is the difference between the total revenue (TR) and the total cost (TC), as shown in Fig. 1(a). In a perfectly competitive market, the selling price is determined by the market and not by the firm itself (Rasmussen, 2012). Under such circumstances, the task of profit maximization is solely to determine the production level $C P_{T}^{*}$ that leads to the highest profit, Profit*. In the accompanying diagram, the corresponding total revenue and total cost are $T R^{*}$ and $T C^{*}$, respectively.

The total revenue $T R$ is the amount of money that a firm receives from the sale of finished goods. It equals the selling price times the number of finished goods. As shown in Fig. 1(a), the establishment of the TR curve is straightforward and it increases linearly. The establishment of the TC curve, however, can be tricky. Each point on the TC curve characterizes the LOWEST cost of producing a specific amount of products. The points on this curve correspond to the cheapest input factor combinations (Rasmussen, 2012). Points above the curve are attainable but unwise, while points below are unattainable given present factors of production.

The total cost $T C$ is the sum of the fixed cost $F C$ and the variable cost $V C$, as shown in Fig. 1(b). In the short run, the fixed cost does not vary. It is incurred by fixed assets such as buildings, machinery, and land, regardless of the production level. An increase or decrease in FC would cause the TC curve to shift up or down by the amount of the change. It has no effect on the TR curve or the shape of the TC curve. Consequently, the optimal production level $C P_{T}{ }^{*}$ corresponding to the greatest profit would remain the same.

By contrast, the variable cost $V C$ changes nonlinearly with the level of production, increasing as more goods are produced. Factors that incur the variable cost often include energy, labor, and materials needed during production. When the prices of inputs (materials) and outputs (products) are determined by external factors and cannot be influenced by the manufacturer, the material cost increases linearly with the amount needed. Therefore, the key to solving the profit maximization problem is to establish the VC curve with the emphasis on the energy and labor costs.

The share of the energy cost in the total cost has been on the rise in manufacturing. This is due to energy price hikes (Carducci, 2013; Wernau, 2014), more stringent $\mathrm{CO}_{2}$ emission regulations (Liu et al., 2015), anddeveloping countries' increasing energy demands (Fang et al., 2011; Rentizelas et al., 2012). Electricity is a major form of energy supplyfor manufacturing activities (U.S. Energy Information Administration, 2013). Constantly evolving technologies have provided both new opportunities and new challenges for manufacturing firms to lower the energy cost. One such technology is electricity demand response (Fernandes et al., 2014; Moghadam et al., 2014; Wang et al., 2014).

Based on the definition ofU.S. Federal Energy Regulatory Commission (2012), demand response refers to a collection of mechanisms that encourage consumers to reduce electric demand during peak periods. A common implementation of the demand response technology is time-varying electricity pricing(Mikhaylidi et al., 2015). Unlike the traditional flat-rate pricing, 
time-varying pricing divides the day into two or three (on-, mid-, and off-peak) periods and allocate a different unit price for each time period. In addition to the traditional energy consumption charge, time-varying pricing also charges the consumer for the peak power demand during a billing cycle. The underlying objective of time-varying pricing is to actively engage customers in modifying their electricity use patterns in response to price signals. Such timevarying rates intend to shift the customer demand from the on-peak period to the off-peak period. If a customer reduces demand during peak hours, their electric bills will be lowered. The utility companies also benefit because they can better balance demand and supply to improve the reliability and sustainability of the entire grid.

Some work has been done in the literature to take advantage of time-varying pricing. For example, from the design and operational perspectives, Wang and Li (2014) have conducted the monotonicity analysis of time-varying pricing-based electricity consumption and cost of manufacturing a product. The work was based on a mathematical model of manufacturing systems proposed in (Wang and Li, 2015). The findings have been used to justify the energy cost savings by switching from the flat rates to the time-varying rates. Wang and Li (2013) have proposed a systems approach from the control perspective for electricity demand response while maintaining a certain level of production. In order to avoid affecting the entire system's throughput, they utilize buffers and allow for temporary stoppage of local work. They have created a schedule to control each machine so their concurrent operations during peak hoursare minimized. However, such works all focus on time-of-use pricing, which is only one type of time-varying pricing programs. The other types of time-varying pricing programs have been overlooked.

Many other scholars have addressed similar problems in a broader literature of production energy management and energy efficiency improvement. Examples include (Brundage et al., 2014; Chen et al., 2013; Frigerio and Matta, 2014; He et al., 2015; Weinert et al., 2011). However, energy efficiency and demand response are two different concepts. The first one focuses more on reduce the energy consumption (measured in $\mathrm{kWh}$ ) and the second one focuses more on lower the peak demand (measured in kW) (Goldman et al., 2010).

In addition, despite much work on this topic, the above-mentioned studies focus on scheduling for manufacturing systems or shifting production from the on-peak period to the offpeak period. For fully-automated or lights-out manufacturing (Davidson, 2011; Null and Caulfield, 2003) where no labor cost is incurred or the labor cost is exceptionally small compared to other cost components, such scheduling activities will lead to the same solutions as profit maximization. However, for manual and semi-automated systems (Fasth et al., 2008), which are still the majority in various manufacturing industries, such activities may not always be aligned with the ultimate goal of profit maximization. This is because employees in various manufacturing industries are usually entitled a shift differential payment for work performed at different time of the day.

Therefore, the labor cost also varies across time of day due to the shift differential. If the labor cost differential at the off-peak period is substantial in comparison to the electricity cost saving, it may not be economical to perform the production shift from the on-peak period to the off-peak period. Therefore, it is important to consider the time-varying electricity and labor costs jointly. The decision will have to be made based on the best trade-off between the labor cost increasing and the electricity cost saving.

It should be mentioned that optimization problems integrating both electricity and labor costs has been initially studied in the literature of manufacturing. For example, Yang et al. (2011) have proposed to optimize the multi-pass face milling process. However, such studies have the following 
limitations: (i) the machines are considered 100\% reliable; (ii) both electricity cost and labor cost are based on the flat rates; (iii) the focus is on the process level optimization (therefore no buffer is considered), instead of the system level optimization.

Motivated by the status quo, we propose to study manufacturing profit maximization where both the electricity pricing and the labor pricing are time varying. It is based on general manufacturing systemsthat consistof multiple unreliable machines and finite buffers. The present paper differs from previous work (Wang and Li, 2013, 2014) in the following aspects. First, it integrates the time-varying labor cost, which was ignored previously.Second, it addresses the problem of profit maximization as a whole, which is the ultimate goal of manufacturing firms. Finally, the problem formulation of profit maximization has implicitly integrated multiple objectives (e.g., minimizing the makespan, minimizing the electricity cost, minimizing the labor cost, and maximizing the profit), while the previous research only focuses on a single objective: minimizing the electricity cost.

\section{Time-varying electricity and labor pricing}

Based on a recent survey by U.S. Federal Energy Regulatory Commission (2012), the most popular time-varying electric pricing in the U.S. is time-of-use (TOU) pricing. A representative profile of the traditional flat-rate pricing is given in Table 1(a)(Orange and Rockland Utilities, 2013a, c). In comparison, the corresponding TOU pricing from the same utility company is given in Table 1(b)(Orange and Rockland Utilities, 2013b, c). In this example, both rates group different months into only two seasons. In addition, both rates involve a monthly fixed charge (or called other charges). Two major differences exist between the flat and TOU rates. First, the entire day is divided into on-peak and off-peak periods in the TOU rate, and the electricityprice of the on-peak period is much higher than the off-peak period. Second, the TOU rate also involves a demand charge, which is measured in $\$ / \mathrm{kW}$.

Another popular time-varying electric pricing is critical-peak pricing (CPP). Many utilities offer CPP as an overlay on the TOU pricing. It imposes a much higher adder to the unit energy price during a period called the critical peak in event days. The number of CPP events is limited per year. Although the electric price is much higher during the critical-peak period in event days, the customers are offered discounted prices or credits during summer days. Therefore, the customers may still lower their electric bills by restraining electric use during CPP events. The time and duration of the critical peak period within an event day are usually predetermined, but the specific dates when the events will occur are not. Generally, the customers will be informed one day ahead of the event. A representative base TOU profile is shown in Table 2(a), the corresponding discounted CPP pricing during non-event days is shown in Table 2(b), and the corresponding price adder during event days is shown in Table 2(c)(San Diego Gas \& Electric, 2015). The differences among these three profiles are underlined.

As for time-varying labor pricing, currently there is no federal requirement of paying shift differentials in the U.S. In practice, the use of different shift work in manufacturing varies greatly from company to company (Rosa and Colligan, 1997). A representative shift differential profile is that the wages will be $100 \%, 107.5 \%$, and $110 \%$ during the first shift (8am-4pm), the second shift (4pm-12midnight), and the third shift (12midnight-8am), respectively (King and Wilmams, 1985; U.S. Office of Personnel Management, 2014). Although some companies still use the flat-wage profile (i.e., the wage is $100 \%$ during any shift), the three-shift differential profile is not rare in manufacturing industry. It is sure that no one gets paid "time and a half" for the overnight shift. That is called overtime pay (U.S. Department of Labor, 2014), which will not be considered in this paper. 


\section{Production function}

The mathematical relationship between the inputs and the produced outputs is revealed in the production function. This paper is concerned with manufacturing systems with $N$ machines and $N-1$ buffers that are connected in series, as shown in Fig. 2.

In order to establish the production function, we consider a finite planning horizon of $H=24$ hours during a workday. The planning horizon is evenly divided into $T$ slots $(t=1$ being the first slot and $t=T$ being the last) with an interval of $t_{C}$, which is the cycle time a machine needs to process a part. Therefore, $T=H / t_{C}$.

Let $C_{i}$ bethe largest number of parts buffer $b_{i}(i=1, \ldots, N-1)$ can hold. It represents the capacity of the buffer.We useh $h_{i}(t)$ to represent the number of parts in the buffer at the end of time slot $t$. The value of $h_{i}(t)$ can change at most by one part in each time slot and it ranges from 0 (empty) to $C_{i}$ (full).

Machines may not be $100 \%$ reliable. Due to random failures, the up probability of machine $m_{i}(i=1, \ldots, N)$ during time slot $t$ is $p_{i}$ and down probability is $1-p_{i}$. Machine states are defined by whether it is working during a time slot. In addition to the up and down states, each machine can be starved, blocked, or both. For example, if buffer $b_{1}$ is empty, then machine $m_{2}$ is starved because no part will be fed into the machine; similarly, if buffer $b_{i}$ is full, then machine $m_{i}$ is blocked because it cannot put any more parts into buffer $b_{i}$. When a machine is up but not producing, it is in the idle state.

In order to establish the production function, we need to first determine buffer state probabilities. At the end of time slot $t$, the probability of buffer $b_{i}(i=1, \ldots, N-1)$ being in state $j$ $\left(j=0, \ldots, C_{i}\right)$ is denoted by $q_{i, j}(t)$. It can be calculated using the methods in (Wang and $\mathrm{Li}, 2014$, 2015).

The first machine is assumed never starved. During time slot $t$, the starvation probability of machine $m_{1}$ is

$$
S T_{1}(t)=0
$$

For machine $m_{i}(i=2, \ldots, N)$,

$$
\begin{aligned}
S T_{i}(t) & =\operatorname{Pr}\left[\left\{m_{i} \mathrm{st}\right\}\right] \\
& =\operatorname{Pr}\left[\left\{m_{i} \mathrm{up}\right\} \cap\left\{h_{i-1}(t-1)=0\right\}\right] \\
& =p_{i} q_{i-1,0}(t-1)
\end{aligned}
$$

The last machine is assumed never blocked. During time slot $t$, the blockage probability of machine $_{N}$ is

$$
B L_{N}(t)=0
$$

For machine $m_{i}(i=1, \ldots, N-1)$,

$$
\begin{aligned}
B L_{i}(t) & =\operatorname{Pr}\left[\left\{m_{i} \text { bl }\right\}\right] \\
& =\operatorname{Pr}\left[\left\{m_{i} \text { up }\right\} \cap\left\{h_{i}(\mathrm{t})=C_{i}\right\} \cap\left\{m_{i+1} \mathrm{npr}\right\}\right] \\
& =\operatorname{Pr}\left[\left\{m_{i} \text { up }\right\} \cap\left\{h_{i}(\mathrm{t})=C_{i}\right\} \cap\left(\left\{m_{i+1} \mathrm{dn}\right\} \bigcup\left\{m_{i+1} \mathrm{st}\right\} \bigcup\left\{m_{i+1} \mathrm{bl}\right\}\right)\right] \\
& =\operatorname{Pr}\left[\left\{m_{i} \text { up }\right\} \cap\left\{h_{i}(\mathrm{t})=C_{i}\right\} \cap\left(\left\{m_{i+1} \mathrm{dn}\right\} \bigcup\left\{m_{i+1} \mathrm{bl}\right\}\right)\right] \\
& =p_{i} q_{i, C_{i}}(t-1)\left[1-p_{i+1}+B L_{i+1}(t)\right]
\end{aligned}
$$

During time slot $t$, the simultaneous blockage and starvation probability of machine $m_{i}(i=1$ or $N$ ) is

$$
B S_{i}(t)=\operatorname{Pr}\left[\left\{m_{i} \mathrm{bl}\right\} \cap\left\{m_{i} \mathrm{st}\right\}\right]=0
$$

For machine $m_{i}(i=2, \ldots, N-1)$, 


$$
\begin{aligned}
B S_{i}(t) & =\operatorname{Pr}\left[\left\{m_{i} \text { bl }\right\} \cap\left\{m_{i} \text { st }\right\}\right] \\
& =\operatorname{Pr}\left[\left\{m_{i} \text { up }\right\} \cap\left\{h_{i}(t)=C_{i}\right\} \cap\left\{m_{i+1} \text { npr }\right\} \cap\left\{m_{i} \text { up }\right\} \cap\left\{h_{i-1}(t-1)=0\right\}\right. \\
& =\operatorname{Pr}\left\{\left\{m_{i} \text { up }\right\} \bigcap\left\{h_{i}(t)=C_{i}\right\} \cap\left[\left\{m_{i+1} \operatorname{dn}\right\} \bigcup\left\{m_{i+1} \text { st }\right\} \bigcup\left\{m_{i+1} \text { bl }\right\}\right] \cap\left\{h_{i-1}(t-1)=0\right\}\right\} \\
& =p_{i} q_{i, C_{i}}(t-1)\left[1-p_{i+1}+B L_{i+1}(t)\right] q_{i-1,0}(t-1)
\end{aligned}
$$

During time slot $t$, the idle probability of machine $m_{i}(i=1, \ldots, N)$ is

$$
I D_{i}(t)=S T_{i}(t)+B L_{i}(t)-B S_{i}(t)
$$

During time slot $t$, the production rate of machine $m_{i}(i=1, \ldots, N)$ is

$$
P R_{i}(t)=p_{i}-I D_{i}(t)
$$

The production rate of the system the same as that of the last machine $m_{N}$,

$$
P R_{S Y S}(t)=P R_{N}(t)
$$

During the planning horizon of $T$ time slots, the system's cumulative production is

$$
C P_{T}=\sum_{t=1}^{T} P R_{S Y S}(t)
$$

\section{Electricity cost function}

Besides the production function, the cost function is also essential for formulating the profit maximization problem. The time-varying electricity cost function will be established in this section. The time-varying labor cost function will be established in the next section.

Tables 1 and 2 reveal that the flat-rate and CPP profiles can both be considered as special cases of the TOU profile. Therefore, we only need to model the electricity cost function based on the TOU rate structure.

Different machine states correspond to different levels of electric demand and energy consumption. For machine $m_{i}$, during time slot $t$, when itis up and processing, it needs $d_{i, 2} \mathrm{~kW}$ of electric power; it needs $d_{i, 1} \mathrm{~kW}$ of electric power when itis up and idle; it needs no power, i.e., $d_{i, 0}$ $=0 \mathrm{~kW}$ when it is down. The corresponding values of energy consumption during a time slot are $e_{i, 2}=d_{i, 2} t_{C} \mathrm{kWh}, e_{i, 1}=d_{i, 1} t_{C} \mathrm{kWh}$, and $e_{i, 0}=0 \mathrm{kWh}$, respectively. In general, $e_{i, 2} \geq e_{i, 1} \geq e_{i, 0}=0$ and $d_{i, 2} \geq d_{i, 1} \geq d_{i, 0}=0$.

During time slot $t$, the expected electricity demand of machine $m_{i}$ is

$$
d_{i}(t)=d_{i, 2} P R_{i}(t)+d_{i, 1} I D_{i}(t)+d_{i, 0} D N_{i}(t)
$$

where $D N_{i}(t)=1-p_{i}$ is machine $m_{i}$ 'sprobability of being down for time slot $t$. During time slot $t$, the power demand of the $N$-machine manufacturing system is

$$
d_{S Y S}(t)=\sum_{i=1}^{N} d_{i}(t)
$$

Assume the electricity demand of the building during time slot $t$ is $d_{B L D}(t) \mathrm{kW}$, which represents the base electricity demand for HVAC, lighting, etc. that support the base building functionality. Then the expected electricity demand of the plant (including the manufacturing system and the building) during time slot $t$ is

$$
d_{\text {PLANT }}(t)=d_{B L D}(t)+d_{S Y S}(t)
$$

The plant's peak demand determines the "charge for demand". The peak demand is the highest average $\mathrm{kW}$ measured during the on-peak intervals of length $t_{D}=15$ minutesfor the entire month(Orange and Rockland Utilities, 2013b).This peak demand is denoted by $d_{T}$. It can be 
obtained using a sliding window search method with a window length of $t_{D}$, as described in (Wang and Li, 2014).During the planning horizon,the electricity demand cost of the system is

$$
c_{D T}=c_{D} d_{T}
$$

where $c_{D}$ is the demand rate $(\$ / \mathrm{kW})$ during the on-peak period.

machine $m_{i}$ 'sexpected electric energy consumption is

$$
e_{i}(t)=e_{i, 2} P R_{i}(t)+e_{i, 1} I D_{i}(t)+e_{i, 0} D N_{i}(t)
$$

During time slot $t$, the $N$-machine manufacturing system'sexpected electric energy consumption is

$$
e_{S Y S}(t)=\sum_{i=1}^{N} e_{i}(t)
$$

The building's electricity consumption is $e_{B L D}(t)=d_{B L D}(t) t_{C}$ kWh. The expected electricity consumption of the plant (including the manufacturing system and the building) during time slot $t$ is

$$
e_{\text {PLANT }}(t)=e_{B L D}(t)+e_{S Y S}(t)
$$

During the planning horizon,the total electricity consumption of the plant is

$$
e_{T}=\sum_{t=1}^{T} e_{\text {PLANT }}(t)
$$

The system's electricity energy cost is

$$
c_{E N R G T}=\sum_{t=1}^{T} c_{E}(t) e_{P L A N T}(t)
$$

where $c_{E}(t)$ is the corresponding TOU rate $(\$ / \mathrm{kWh})$ for time slot $t$.

The total daily electricity cost can be formulated as

$$
c_{E T}=c_{D T}+c_{E N R G T}+c_{O T}
$$

where $c_{O T}$ represents other charges during the planning horizon. We consider a planning horizon

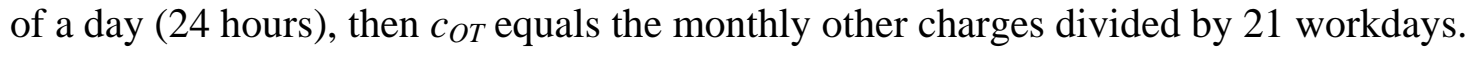

\section{Labor cost function}

This section establishes the time-varying labor cost function. The flat wage profile is a special case of the wage profile with shift differentials. Therefore, we only need to model the labor cost function based on the more complicated time-varying profile of the labor rate.

Let $t_{i, \text { start }}$ and $t_{i, \text { end }}$ be the start and end time, respectively, for machine $m_{i}(i \in\{1,2, \ldots, N\})$ during a 24-hour period. Let $t_{i, d u r}$ be the time duration of machine $m_{i}$ 's operation. The following relationship holds:

$$
t_{i, \text { end }}=t_{i, \text { start }}+t_{i, \text { dur }}
$$

wheret $_{i, \text { start }} \in\{1,2, \ldots, T\}$ and $t_{i, d u r} \in\{1,2, \ldots, T\}$. The production makespan (i.e., the time difference between the start and end of a sequence of production jobs) during a 24-hour period satisfies

$$
\max _{i \in\{1,2, \ldots, N\}} t_{i, \text { end }}-\min _{i \in\{1,2, \ldots, N\}} t_{i, \text { start }} \leq T
$$

where $\max _{i \in\{1,2, \ldots, N\}} t_{i, \text { end }}$ and $\min _{i \in\{1,2, \ldots, N\}} t_{i \text {,start }}$ represent the latest end time and the earliest start time, respectively. 
Let $c_{L}(t)$ be the labor rate $(\$ / \mathrm{Mh})$ during time slot $t$. "Mh" is the abbreviation for "man hour(s)". The labor rate is the same for all the workers and it varies at different work shifts. The $100 \%$ base labor rate can be estimated based on the survey of U.S. Department of Labor Bureau of Labor Statistics (2014). For the private industry sector, the latest average labor rate (including wages and benefits) is equivalent to $\$ 29.63 / \mathrm{Mh}$. Let $w$ be the number of workers. Different levels of automation need different numbers of workers (Fasth et al., 2008, 2010). In general, for a specific manufacturing plant, the higher the automation level, the fewer the workers needed. Theoretically, a manufacturing system with $100 \%$ automation needs no worker.

The labor cost is incurred if at least one machine is in operation. The total labor cost during the makespan is

$$
C_{L T}=w \cdot \sum_{t=\sum_{i \in\{1,2, \ldots, N\}}}^{\max _{i \in\{1,2, \ldots, N\}} t_{i, \text { start }}}\left[c_{L}(t) \cdot t_{C}\right]
$$

During time slot $t$, we uses $i(t)$ to denote the status of the scheduled control signal for machine $m_{i}$. It is defined as

$$
s_{i}(t)= \begin{cases}1, & \text { if } t_{i, \text { start }} \leq t \leq t_{i, \text { end }} \\ 0, & \text { otherwise }\end{cases}
$$

Then, an alternative form of $c_{L T}$ is

$$
c_{L T}=w \cdot \sum_{t=1}^{T}\left[c_{L}(t) \cdot t_{C} \cdot \bigcup_{i=1}^{N} S_{i}(t)\right]
$$

\section{Manufacturing profit maximization}

\subsection{Problem formulation}

This paper is concerned with profit maximization under perfect competition. It is based on the assumption that the prices of inputs (materials) and outputs (products) are determined by external factors and cannot be changed by the producer. We assume the material and product prices are $r_{1}$ and $r_{2}$, respectively. The material cost is

$$
c_{M T}=r_{1} \cdot C P_{T}
$$

The variable cost during the planning horizon is

$$
V C=C_{E T}+C_{L T}+C_{M T}
$$

The total cost during the planning horizon is

$$
T C=V C+F C
$$

The total revenue during the planning horizon would be

$$
T R=r_{2} \cdot C P_{T}
$$

The profit would be

$$
\text { Profit }=T R-T C
$$

For the $N$-machine manufacturing system, the problem is formulated to determine the production level $C P_{T}$ so that the profit is maximized during the planning horizon. If the profit curve in Fig. 1(a) is known, this can be easily done by graphically examining the curve. Based on the decomposition of the profit and cost curves in Fig. 1, both $T R$ and FC can be easily obtained. Therefore, the key to solving the profit maximization problem is to establish the $V C$ curve. Similarly, since the material cost $c_{M T}$ can also be easily obtained, we only need to establish the energy and labor costs $c_{E T}+c_{L T}$. More specifically, we need to determine the start time $t_{i, s t a r t}$ and 
duration $t_{i, d u r}$ of each machine $m_{i}(i=1, \ldots, N)$ so $c_{E T}+c_{L T}$ is the lowest for every specific production level $C P_{0}$. That is,

$$
\begin{array}{ll}
\min _{t_{i, \text { sart }}, t_{i, \text { dur }}} & C_{E T}+C_{L T} \\
\text { subject to } & C P_{T} \geq C P_{0}
\end{array}
$$

\subsection{Solutions to the steady-state case}

We first consider the steady-state case where all the machines start simultaneously at the beginning and they stop simultaneously at the end of the operation. Under such circumstances, all the buffers are properly filled at the beginning (or at the end of the previous operation) so there are no transients and no production loss due to transients (Meerkov and Zhang, 2008; Wang and $\mathrm{Li}$, 2015). The steady-state case is suitable for non-perishable products where the buffers do not have to be emptied at the end of each day's operation.

For the steady-state case, we only need to determine the start time $t_{i \text {,start }}$ and the duration $t_{i \text {,dur }}$ of a single machine $m_{i}$. There are a total of $T \cdot T=T^{2}$ possible combinations. The optimal solutions can be obtained by using the following algorithm. Exhaustive search means every of the possible solutions has to be examined to check if it is optimal. Therefore, the final solution is guaranteed to be the optimal solution.

Algorithm 1 (Exhaustive search).

Step 1: The steady state can be achieved by following the procedure in (Wang and $\mathrm{Li}$, 2015). At the steady state, the performance measures in (1) through (9) can be calculated and they are all constant. The cumulative production in (10) can be rewritten as

$$
C P_{T}=T \cdot P R_{S Y S}
$$

Step 2: The duration can be determined easily. In order to satisfy the constraint for a specific $C P_{0}$, we have $T \cdot P R_{S Y S} \geq C P_{0}$, i.e., $T \geq C P_{0} / P R_{S Y S}$. Therefore,

$$
t_{i, \text { dur }}=\left\lceil C P_{0} / P R_{\text {SYS }}\right\rceil
$$

Step 3: Now we only need to determine start time $t_{i, \text { start }}$. Exhaustively search for each $t_{i, \text { start }}$ $\epsilon\{1,2, \ldots, T\}$ and find the one with the lowest $c_{E T}+c_{L T}$.

Example 1 (Steady-state case). We consider a system with $N=8$ machines and 7 buffers in this example. The cycle time of each machine is $t_{C}=15$ minutes. The electric power levels of the eight machines are [20 4 0], [30 8 0], [15 5 0], [35 3 0], [25 3 0], [20 7 0], [23 10 0], [32 5 0], respectively, in the form of $\left[d_{i, 2} d_{i, 1} d_{i, 0}\right] \mathrm{kW}$. The building's power demand is $d_{B L D}=30 \mathrm{~kW}$. The system is highly automated and only needs $w=2$ workers to operate. The summer TOU rates are adopted. We consider the cases thatthe machines have the identical reliability $p_{i}=0.95$ and the buffers have the identical capacity $C_{i}=3$. It should be mentioned that this is only for the convenience of displaying the results graphically. The algorithms and the modeling in this paper can deal with the cases where buffers have different capacities and machines have different reliabilities. The production level $C P_{0}=30$.

After applying Algorithm 1, we plot the results of this example in Fig. 3. The figure can be explained as follows.

(i) Figs. 3(a) and 3(b) are the time-varying energy and demand rates of the TOU summer pricing profile. These two profiles are based on the values in of Table 1(b). Fig. 3 (c) is the time-varying labor pricing profile. The base wage is $\$ 29.63 / \mathrm{Mh}$. 
(ii) The horizontal axes of (a), (b), (c), and (h) in Fig. 3 represent the time of day. The horizontal axes of (d) through (g) represent the start time $t_{i, \text { start }}$ during the day.

(iii) Fig. 3(d) shows how the electricity energy cost $c_{E N R G T}$ will change over the production start time $t_{i, s t a r t}$ as the horizontal axis. If the production starts between 7pm and 4:45am (next day), it will be completed entirely within off-peak periods and $c_{E N R G T}=\$ 186.40$. If the production starts after 4:45am, it will be partially fall into the on-peak periodwith higher energy charge. As the portion that falls in the on-peak period continue to increase, $C_{E N R G T}$ also increases.

(iv) Fig. 3(e) shows how the demand cost $c_{D T}$ will change over the production start time in the horizontal axis. Similar to Fig. 3(d), the demand cost is zero if the production starts between 7pm and 4:45am because the production is completed entirely within off-peak periods. The demand cost is only imposed when the production at least partially falls into the on-peak period.

(v) Fig. 3(f) shows how the labor cost $c_{L T}$ will change over the production start time. It decreases constantly from 0:00 to 8am because the production happens more and more in the first-shift hours (when labor costs less), and less and less in the third-shift hours (when labor costs more). The labor cost will increase after 8am, because the production will have to involve more second-shift hours. After 4pm, it will continue to increase because more third-shift hours will be needed.

(vi) Fig. 3(g) is the combined electricity cost and labor cost. Graphically, it is just the sum of Figs. 3(d) through 3(f). The minimal $c_{E T}+c_{L T}=\$ 696.99\left(c_{D T}=\$ 0, c_{E N R G T}=\$ 186.40\right.$, $c_{O T}=\$ 2.44$, and $c_{L T}=\$ 508.15$ ) is achieved when $t_{i, \text { start }}=20$ (i.e., 4:45am). The corresponding actual $C P_{T}=30.1014$.

(vii) Fig. 3(h) shows the final control signal for each machine that leads to the minimal $c_{E T}+$ $c_{L T}$. The duration of the operation $t_{i, d u r}=34$ (i.e., 8.25 hours), which is the length of the segment when the signal is on, i.e., $s_{i}(t)=1$. Therefore, for the steady-state case, the minimal $c_{E T}+c_{L T}$ (and correspondingly the maximal profit) will be achieved when the production lasts for 8.25 hours. Longer or shorter production hours will both increase the minimal $c_{E T}+c_{L T}$ and thus reduce profit.

(viii) It should be noted that in order to keep $t_{i, \text { end }}$ in the range $\{1,2, \ldots, T\}$, the value larger than $T$ is wrapped around. For example, for $T=96$ time slots, if the machines start from $t_{i, \text { start }}=77$ (i.e., $8 \mathrm{pm}$ ) and the work duration $t_{i, d u r}=32$ (i.e., 8 hours), then the end time should be $t_{i, \text { end }}=t_{i \text {,start }}+t_{i, \text { dur }}=77+32=109$. Since it is larger than 96 , we need to use the wrap-around operation to map the value back to the range $\{1,2, \ldots, 96\}$. After the wrap-around operation, $t_{i, \text { end }}=\bmod \left(t_{i, \text { end }}, 96\right)=13$ (i.e., $4 \mathrm{am}$ next day). Mathematically, $t_{i, \text { end }}$ is updated by

$$
t_{i, \text { end }} \Leftarrow \begin{cases}t_{i, \text { end }}, & \text { if } t_{i, \text { end }} \leq T \\ \bmod \left(t_{i, \text { end }}, T\right), & \text { otherwise }\end{cases}
$$

where $\bmod (\cdot, \cdot)$ is the modulo operation.

\subsection{Solutions to the transient case}

In the steady state,the production system operates at a more synchronized pace. In comparison, transient behaviorsoccur before reaching the steady state. One common scenario that will introduce transients is when the buffers are all empty at the beginning of production. All the machines(except the first)are starved before its upstream buffer is at least partially filled. The mean values of the performance measuresduring the transients, e.g., $B L_{i}(t), S T_{i}(t), I D_{i}(t), B S_{i}(t)$, 
and $P R_{i}(t)$ in Equations (2) through (9), can vary and be different from those of the steady state. The values will keep changing over time. Such factors make the optimization problem (32) highly nonlinear and make it more difficult to determine the optimal solution.

We now consider the transient case where all the machines can start asynchronously at the beginning and they can stop asynchronously at the end of the operation. Under such circumstances, the operation begins with a fresh start and all the buffers are empty so that transients will occur. The transient case is suitable for perishable products (Wang et al., 2010) or processes with technological requirements (Meerkov et al., 2010) and at the end of each day's operation, the buffers have to be depleted.

Therefore, we need to determine the start time $t_{i, \text { start }}$ and duration $t_{i, \text { dur }}$ of each machine $m_{i}(i$ $=1, \ldots, N)$. There are $T \cdot T=T^{2}$ possible combinations for a single machine $m_{i}$, and there are a total of $T^{2 N}$ possible combinations for the $N$-machine system.

Finding the optimal solutions for the transient case is a huge challenge. The difficulty lies in the fact that the calculation of the cumulative production $C P_{T}$ is non-linear. In this section, we use a meta-heuristic called particle swarm optimization (PSO) to solve the problem formulation. PSO is a generic algorithm commonly utilized in both academia and industry(Faria et al., 2011; Martens et al., 2011; Roy et al., 2008; Soares et al., 2012; Thangaraj et al., 2011; Wang and Li, 2012). It does not required the problem to be convex, continuous, or differentiable. The PSO algorithm utilized in (Wang and $\mathrm{Li}, 2012$ ) is tailored to find the approximate solutions for this research.

\section{Algorithm 2 (Particle swarm optimization).}

Step 1: A particle is represented by a velocity matrix $\varsigma$ and a position matrix $\mathrm{T}$. The position matrix Tas shown below isaencoded potential solution to (31)

$$
\mathbf{T} \equiv\left[\begin{array}{llll}
t_{1, \text { start }} & t_{2, \text { start }} & \cdots & t_{N, \text { start }} \\
t_{1, \text { dur }} & t_{2, \text { dur }} & \cdots & t_{N, \text { dur }}
\end{array}\right]
$$

The velocity matrix chas the same size as the position matrix, and it modifies $\mathbf{T}$ iteratively during the search.

Step 2: A swarm of $N_{P}$ particles was generated. Initialize the position matrix $\mathbf{T}$ of all the particles with the steady-state solution obtained by Algorithm 1. Initialize each element of $\varsigma$ with random integer numbers drawn from the set $\{-1,0,1\}$. Set the iteration counter to zero.

Step 3: Calculate the objective function $c_{E T}+c_{L T}$ and the constraint $C P_{T}$ of all particles. Update the personal best $\mathbf{T}_{P B}$ of each particle and global best $\mathbf{T}_{G B}$ of the swarm. $\mathbf{T}_{P B}$ is thepersonal best solution that the particle has found so far. $\mathbf{T}_{G B}$ is theglobal best solution of the entire swarm found so far.

Step 4: At each iteration, each particle's velocity matrix is updated as follows

$$
\begin{aligned}
\mathbf{V}(i, j)=\theta_{0} \cdot \mathbf{V}(i, j) & +\operatorname{rand}\left(0, \theta_{1}\right) \cdot\left[\mathbf{T}_{P B}(i, j)-\mathbf{T}(i, j)\right] \\
& +\operatorname{rand}\left(0, \theta_{2}\right) \cdot\left[\mathbf{T}_{G B}(i, j)-\mathbf{T}(i, j)\right]
\end{aligned}
$$

and then each element in the velocity matrix is capped by

$$
\mathbf{V}(i, j)=\left\{\begin{array}{l}
-1, \text { if } \mathbf{V}(i, j) \leq-0.5 \\
0, \quad \text { if }-0.5<\mathbf{V}(i, j)<0.5 \\
1, \quad \text { if } \mathbf{V}(i, j) \geq 0.5
\end{array}\right.
$$

The position matrix is then updated by 


$$
\mathbf{T}(i, j)=\mathbf{T}(i, j)+\mathbf{V}(i, j)
$$

The index $(i, j)$ in (36) through (38) denotes the element in the $i$ th row and $j$ th column; random numbers from the uniform distribution will be generated byrand $(0$, $\left.\theta_{1}\right)$ and $\operatorname{rand}\left(0, \theta_{2}\right)$ in the range $\left[0, \theta_{1}\right]$ and $\left[0, \theta_{2}\right]$, respectively; $\theta_{0}$ is a scalar inertial weight.

Step 5: Plus one on the iteration counter. Check if a certain number of PSO iteration $N_{T}$ is reached. If it is, then terminate the algorithm and output $\mathbf{T}_{G B}$ as the solution; otherwise, go to Step 3.

Example 2 (Transient case). In this example, all the parameters $\left(N, t_{C}, w, C_{i}, p_{i}\right.$, machine and building power levels, summer TOU rates, base wage, and $C P_{0}$ ) are the same as in Example 1. The PSO parameters recommended in (Trelea, 2003; Wang and Li, 2012) (i.e., $\theta_{0}=0.6$ and $\theta_{1}=$ $\theta_{2}=1.7$ ) are adopted. Particle size $N_{P}=100$, and the number of PSO iteration $N_{T}=100$.

After applying Algorithm 2, we achieve the following results:

(i) The approximate solution is

$$
\begin{aligned}
& \mathbf{T}=\left[\begin{array}{llll}
t_{1, \text { start }} & t_{2, \text { start }} & \cdots & t_{N, \text { start }} \\
t_{1, \text { dur }} & t_{2, \text { dur }} & \cdots & t_{N, \text { dur }}
\end{array}\right]=\left[\begin{array}{llllllll}
9 & 10 & 11 & 12 & 13 & 15 & 17 & 18 \\
33 & 34 & 35 & 37 & 37 & 36 & 35 & 35
\end{array}\right], \\
& \text { with } c_{E T}+c_{L T}=\$ 1063.80\left(c_{D T}=\$ 27.73, c_{E N R G T}=\$ 346.21, c_{O T}=\$ 2.44 \text {, and } c_{L T}=\right. \\
& \$ 687.42) . \\
& {\left[\begin{array}{lllllllll}
t_{1, \text { end }} & t_{2, \text { end }} & \cdots & t_{8, \text { end }}
\end{array}\right]=\left[\begin{array}{llllllll}
41 & 43 & 45 & 48 & 49 & 50 & 51 & 52
\end{array}\right] . \text { The actual } C P_{T}=}
\end{aligned}
$$

30.0189, which is larger than the constraint $C P_{0}=30$.

(ii) The start time $t_{i, \text { start }}$ is arranged progressively to save the electricity cost because the buffers are empty at the beginning, and each buffer needs some time to be properly filled up so the next machine will have some parts to work on.

(iii) The end time $t_{i, \text { end }}$ is also arranged progressively to save the electricity cost because the buffers may still have work-in-process at the end, and each buffer needs some time to be properly depleted so there will not have too much work-in-process to be wasted.

\subsection{Profit maximization}

With $C_{E T}+C_{L T}$ being available, the curves of VC, TC, TR, and Profit can be established sequentially based on (27)through (30). The maximal profit Profit* and the corresponding optimal production level $\mathrm{CP}_{T}{ }^{*}$ can be identified graphically. This is demonstrated in the following example for the steady-state case. This method is applicable to the transient case as well.

Example 3 (Steady-state case). All the parameters are the same as Example 1. Suppose the material and product prices as well as the fixed cost are known, and they are $r_{1}=\$ 70, r_{2}=\$ 105$, and $F C=\$ 100$, respectively. The results of various curves for the profit maximization problem are shown in Fig. 4. The figure can be explained as follows.

(i) Fig. 4(a) shows the curve of min $\left(c_{E T}+c_{L T}\right)$. The curve is obtained using Algorithm 1 for $C P_{0}$ ranging from 0 to the maximal achievable production level with the given system parameters. The curve appears to be divided into two segments. The reason for this is that the duration $t_{i, d u r}$ needed to maintain $C P_{0}<66$ is short enough that the electricity demand charge can always be avoided by prohibiting the operation during the on-peak period, while the duration $t_{i, d u r}$ needed to maintain $C P_{0} \geq 66$ is long enough that the demand charge is unavoidable.

(ii) Fig. 4(b) shows the total revenue and total cost curves, calculated using (28)and (29). 
(iii) Fig. 4(c) shows the profit, calculated using (30). The maximal profit is $\$ 653.22$, it is achieved when $C P_{T}=65.6758$. A production level higher than this would hurt the profit because the peak electricity demand charge would have to be imposed.

\section{Effects of various parameters on the profit maximization solutions}

In this section, we examine the effects of various parameters on the profit maximization solutions for the system with $N=8$ machines and $t_{C}=15 \mathrm{~min}$. This is done by changing one or two parameters at a time on the baseline case (time-varying summer TOU rates, time-varying labor pricing, $w=2$ workers, buffer capacity $C_{i}=3$ for $i=1, \ldots, N-1, p_{i}=0.95$ for $i=1, \ldots, N-$ 1 , steady-state case) and then comparing the resultant profit curves.The ranges of the parameters for the numerical investigation are given in each subsection. The power demand values of the machines are given in Example 1.

\subsection{Effects of the TOU seasons}

The profit curves based on the summer and winter TOU rates are plotted in Fig. 5(a). Similar to the case with summer TOU rates, the profit curve of the case with winter TOU rates has a generally increasing trend. Due to the imposition of the electric demand charge, it is also split into two segments. However, for the case with winter TOU rates, the slope of the second segment is larger than the counterpart of the case with summer TOU rates. Therefore, the maximal profit is achieved when $C P_{T}=87.5678$, that is, with full production.

\subsection{Effects of the number of workers}

The profit curves based on different numbers of workers ( $w=0,2$, and 4$)$ are plotted in Fig. 5(b). The case with $w=0$ corresponds to the $100 \%$ automation level. With the labor cost totally removed, the manufacturers will enjoy increased profit at full production $\left(C P_{T}=87.5678\right)$. In comparison, with $w$ increases from 2 to 4, which corresponds to a lower automation level, the revenue is eaten up by the increased labor cost, and it would not be profitable at any level of production.

\subsection{Effects of the buffer capacity}

The profit curves based on different buffer capacities $\left(C_{i}=1,3\right.$, and 5) are plotted in Fig. 6(a). As buffer capacity increases, the profit curve rotates upwards. The maximal profit increases and the corresponding optimal production level also increases. All the maximal profits achieve before the electricity demand cost is imposed. However, the difference between $C_{i}=3$ and 5 is much smaller than the difference between $C_{i}=1$ and 3 . That is, the maximal profit saturates as the buffer capacity increases.

\subsection{Effects of the machine reliability}

The profit curves based on different machine reliabilities $\left(p_{i}=0.91,0.95\right.$, and 0.99$)$ are plotted in Fig. 6(b). As reliability increases, the profit curve rotates upwards. The maximal profit increases and the corresponding optimal production level also increases. All the maximal profits achieve before the electricity demand cost is imposed. The difference between $p_{i}=0.91$ and 0.95 is approximately the same as the difference between $p_{i}=0.95$ and 0.99 .

\subsection{Effects of the initial condition}


The profit curves based on the different initial conditions (steady-state and transient) are plotted in Fig. 7(a). Similar to the case starting from the steady state, the profit curve of the case starting with transients has a generally increasing trend. Due to the imposition of the electric demand charge, it is split into two segments, although the transition between the two segments is smoother than the steady case. The slopes of these two segments are approximately the same as the slopes of the two segments of the case starting from the steady state. In general, the transient case is shifted downwards compared to the steady-state case. Transients have compromised the revenue gain, which hinders the profit.

\subsection{Effects of the time-varying pricing}

The profit curves based on different combinations of the time-varying pricing are plotted in Fig. 7(b). "BothVary" represents both electricity and labor pricing are time-varying. "VaryElectric" represents time-varying electricity pricing only. "VaryWage" represents timevarying labor pricing only. "BothFlat" represents both the electricity and labor pricing are flat.

The following can be observed.

(i) The profit curve of VaryWage is lower than the profit curve of BothFlat. This is due to the extra shift differential with time-varying labor pricing.

(ii) The profit curve of VaryElectric is higher than the profit curve of BothFlat. This is because the production can be switched to add more off-peak hours when the TOU rates are much lower than the flat rates.

(iii) The profit curve of BothVary is lower than the profit curve of VaryElectric. This is also due to the extra shift differential with the time-varying labor pricing.

(iv) The profit curve will be split into two segments only when the time-varying electricity pricing is adopted. If no time-varying electricity pricing is involved, the profit curve will have only one segment and the optimal production level is always full production.

\subsection{Effects of TOU vs. CPP}

As mentioned in Section 2, although the time and duration of the critical peak period within an event day are usually predetermined, the specific dates when the events will occur are not. CPP will surely introduce randomness into the profit maximization problem. Therefore, we need to take a different perspective. In this paper, we calculate the expected values using historical event-date information over the last 10 years (2005 through 2014). Such information for the TOU and CPP rates in Table2 are available from California Public Utilities Commission (2014). A summary of the numbers of CPP events by month is shown in Fig. 8(a). There are a total of 60 events during the last 10 years, mostly distributed from June to October.

The profit curves based on four different combinations are plotted in Fig. 8(b). "CPPSummer" and "CPPWinter" represent the average profits when the summer and winter CPP rates, respectively, in Tables 2(b) and 2(c) are used. "TOUSummer" and "TOUWinter" represent the average profits when the summer and winter TOU rates, respectively, in Table 2(a) are used.

The following can be observed.

(i) The profit curve of CPPSummer is lower than the profit curve of CPPWinter. This is due to the fact that both the energy and demand rates for the summer months are higher than those for the winter months.

(ii) The profit curve of TOUSummer is lower than the profit curve of TOUWinter. This is also due to the rate differences between the summer months and winter months. 
(iii) The profit curve of CPPSummer is higher than the profit curve of TOUSummer. This means the customers can lower their electric bills by switching from TOU to CPP because the credits outweigh the adder, which is only imposed during a limited number of event days.

(iv) There is no difference between the profit curves CPPWinter and TOUWinter because the credit and adder are only imposed on the prices during summer months and not on the prices during winter month.

\section{Conclusions and future work}

This paper addresses the manufacturing profit maximization problem considering timevarying electricity and labor pricing. We have established the production function of the manufacturing system. Then, the time-varying electricity cost and the time-varying labor cost have been modeled. The problem formulation of manufacturing profit maximization and the solution techniques are provided. The effects of time-varying electricity and labor pricing on profit maximization solutions have been examined. Although the numerical results obtained are for the examples with specific parameters given in this paper, the established methodology is general and not limited to the scenarios examined.

The flat, TOU, and CPP rates used in this paper are all take from real utility companies' rate books. These rates have been applied to many industrial customers in respective regions such as New York and California. Utilities at other states in the US or other countries may offer different tariffs. It would be interesting to find out what difference it would make if a business were located in different places. The location could also be included into the optimization problem as a decision variable to further explore the possibilities of maximizing the profit for large industrial corporations.

In this work, we specifically refer to time-varying electricity pricing as the TOU and CPP rates. There are other types of time-varying electricity pricing programs. Real-time pricing (RTP), for example, is also a trending technology offered by utility companies across the U.S. There are already some pilot RTP programs (ComEd, 2014; Georgia Power, 2011; West Penn Power Company, 2012). Instead of dividing the day into on- and off-peak periods like TOU or CPP, the electric price in RTP can vary more frequently, for example, by hours or even minutes, and the real price is usually unknown in advance. Therefore, it would be more challenging to adopt RTP in manufacturing for decision making regarding profit maximization. RTP has great potentials comparable to TOU and CPP. It is worth studying as a future goal.

\section{References}

Beattie, B.R., Taylor, C.R., Watts, M.J., 2009. The Economics of Production (2nd Edition). Krieger Publishing Company.

Brundage, M.P., Chang, Q., Li, Y., Xiao, G., Arinez, J., 2014. Energy efficiency management of an integrated serial production line and HVAC system. IEEE Transactions on Automation Science and Engineering, 11(3), 789-797.

California Public Utilities Commission, 2014. Demand Response Monthly Reports. Retrieved from http://www.cpuc.ca.gov/PUC/energy/Demand+Response/Monthly+Reports/.

Carducci, A., 2013. Global warming programs force hike in California power bills. Retrieved Oct. 23, 2014, from http://news.heartland.org/newspaper-article/2013/06/10/global-warming-programsforce-hike-california-power-bills. 
Chen, G., Zhang, L., Arinez, J., Biller, S., 2013. Energy-efficient production systems through schedulebased operations. IEEE Transactions on Automation Science and Engineering, 10(1), 27-37.

ComEd, 2014. Guide to real-time pricing. Retrieved Oct. 23, 2014, from https://www.comed.com/Documents/customer-service/rates-pricing/real-timepricing/RRTPProgramGuide.pdf.

Davidson, K., 2011. More factories turn to automation for the night shift. Retrieved Oct. 23, 2014, from http://www.marketplace.org/topics/business/more-factories-turn-automation-night-shift-0.

Fang, K., Uhan, N., Zhao, F., Sutherland, J.W., 2011. A new approach to scheduling in manufacturing for power consumption and carbon footprint reduction. Journal of Manufacturing Systems, 30(4), 234-240.

Faria, P., Vale, Z., Soares, J., Ferreira, J., 2011. Demand response management in power systems using a particle swarm optimization approach. IEEE Intelligent Systems, 28(4), 43-51.

Fasth, A., Stahre, J., Dencker, K., 2008. Measuring and analysing Levels of Automation in an assembly system, In: Mitsuishi, M., Ueda, K., Kimura, F. (Eds.), Manufacturing Systems and Technologies for the New Frontier - The 41st CIRP Conference on Manufacturing Systems May 26-28, 2008, Tokyo, Japan, Springer London, pp. 169-172.

Fasth, A., Stahre, J., Dencker, K., 2010. Level of automation analysis in manufacturing systems. In: Proceedings of the 3rd international conferens on applied human factors and ergonomics, Miami, Florida, USA. 1-10.

Fernandes, F., Morais, H., Vale, Z., Ramos, C., 2014. Dynamic load management in a smart home to participate in demand response events. Energy and Buildings, 82, 592-606.

Frigerio, N., Matta, A., 2014. Energy-efficient control strategies for machine tools with stochastic arrivals. IEEE Transactions on Automation Science and Engineering, PP(99), 1-12.

Georgia Power, 2011. Real time pricing - Day ahead schedule: "Rtp-da-3". Retrieved Oct. 1, 2014, from http://www.georgiapower.com/pricing/files/rates-and-schedules/6.20_RTP-DA-3.pdf.

Goldman, C., Reid, M., Levy, R., Silverstein, A., 2010. Coordination of Energy Efficiency and Demand Response. Retrieved Oct. 23, 2015, from https://emp.lbl.gov/sites/all/files/REPORT\%20lbnl3044e.pdf.

Hackman, S.T., 2008. Production Economics: Integrating the Microeconomic and Engineering Perspectives. Springer.

He, Y., Li, Y., Wu, T., Sutherland, J.W., 2015. An energy-responsive optimization method for machine tool selection and operation sequence in flexible machining job shops. Journal of Cleaner Production, 87(0), 245-254.

Kalir, A., Arzi, Y., 1997. Automated production line design with flexible unreliable machines for profit maximization. International Journal of Production Research, 35(6), 1651-1664.

King, S.L., Wilmams, H.B., 1985. Shift work pay differentials and practices in manufacturing. Retrieved Oct. 1, 2014, from http://www.bls.gov/opub/mlr/1985/12/art6full.pdf.

Kumar, S., Chatterjee, A.K., 2015. A profit maximising product line optimisation model under monopolistic competition. International Journal of Production Research, 53(5), 1584-1595.

Liu, B.Y., Holmbom, M., Segerstedt, A., Chen, W.D., 2015. Effects of carbon emission regulations on remanufacturing decisions with limited information of demand distribution. International Journal of Production Research, 53(2), 532-548.

Martens, D., Baesens, B., Fawcett, T., 2011. Editorial survey: Swarm intelligence for data mining. Machine Learning, 82(1), 1-42.

Meerkov, S.M., Shimkin, N., Zhang, L., 2010. Transient behavior of two-machine geometric production lines. IEEE Transactions on Automatic Control, 55(2), 453-458.

Meerkov, S.M., Zhang, L., 2008. Transient behavior of serial production lines with Bernoulli machines. IIE Transactions, 40(3), 297-312.

Mikhaylidi, Y., Naseraldin, H., Yedidsion, L., 2015. Operations scheduling under electricity time-varying prices. International Journal of Production Research, 53(23), 7136-7157. 
Moghadam, M.R.V., Ma, R.T.B., Zhang, R., 2014. Distributed frequency control in smart grids via randomized demand response. IEEE Transactions on Smart Grid, 5(6), 2798-2809.

Null, C., Caulfield, B., 2003. Fade to black the 1980s vision of "lights-out" manufacturing, where robots do all the work, is a dream no more. Retrieved Oct. 23, 2014, from http://money.cnn.com/magazines/business2/business2_archive/2003/06/01/343371/index.htm.

Orange and Rockland Utilities, 2013a. Service classification No. 2. Retrieved September 1, 2014, from https://www.oru.com/documents/tariffsandregulatorydocuments/ny/electrictariff/electricsc02.pdf.

Orange and Rockland Utilities, 2013b. Service classification No. 20. Retrieved September 1, 2014, from https://www.oru.com/documents/tariffsandregulatorydocuments/ny/electrictariff/electricsc20.pdf.

Orange and Rockland Utilities, 2013c. Statement of market supply charge. Retrieved September 1, 2014, from

https://www.oru.com/documents/tariffsandregulatorydocuments/ny/electricmarketsupplycharge/ MSC3-18.pdf.

Rasmussen, S., 2012. Production Economics: The Basic Theory of Production Optimisation (2nd Edition). Springer.

Rentizelas, A.A., Tolis, A.I., Tatsiopoulos, I.P., 2012. Investment planning in electricity production under $\mathrm{CO}_{2}$ price uncertainty. International Journal of Production Economics, 140(2), 622-629.

Rosa, R.R., Colligan, M.J., 1997. Plain language about shiftwork. Retrieved Oct. 23, 2014, from http://www.cdc.gov/niosh/docs/97-145/.

Roy, R., Hinduja, S., Teti, R., 2008. Recent advances in engineering design optimisation: Challenges and future trends. CIRP Annals-Manufacturing Technology, 57(2), 697-715.

San Diego Gas \& Electric, 2015. Current and Effective Tariffs. Retrieved from www.sdge.com/ratesregulations/current-and-effective-tariffs/current-and-effective-tariffs.

Soares, J., Silva, M., Sousa, T., Vale, Z., Morais, H., 2012. Distributed energy resource short-term scheduling using signaled particle swarm optimization. Energy, 42(1), 466-476.

Thangaraj, R., Pant, M., Abraham, A., Bouvry, P., 2011. Particle swarm optimization: Hybridization perspectives and experimental illustrations. Applied Mathematics and Computation, 217(12), 5208-5226.

Trelea, I.C., 2003. The particle swarm optimization algorithm: Convergence analysis and parameter selection. Information Processing Letters, 85(6), 317-325.

Trigos, F., López, E.M., 2016. Maximising profit for multiple-product, single-period, single-machine manufacturing under sequential set-up constraints that depend on lot size. International Journal of Production Research, 54(4), 1134-1151.

U.S. Department of Labor - Bureau of Labor Statistics, 2014. Employer costs for employee compensation - December 2013. Retrieved Oct. 1, 2014, from http://www.bls.gov/news.release/pdf/ecec.pdf.

U.S. Department of Labor, 2014. Overtime pay. Retrieved Oct. 23, 2014, from http://www.dol.gov/dol/topic/wages/overtimepay.htm.

U.S. Energy Information Administration, 2013. International energy outlook. Retrieved Oct. 1, 2013, from http://www.eia.gov/forecasts/ieo/pdf/0484(2013).pdf.

U.S. Federal Energy Regulatory Commission, 2012. Assessment of demand response and advanced metering staff report. Retrieved Oct. 15, 2014, from http://www.ferc.gov/legal/staff-reports/1220-12-demand-response.pdf.

U.S. Office of Personnel Management, 2014. Fact sheet: Night shift differential for federal wage system employees. Retrieved Oct. 1, 2014, from https://www.opm.gov/policy-data-oversight/payleave/pay-administration/fact-sheets/night-shift-differential-for-federal-wage-system-employees/.

Wang, J., Hu, Y., Li, J., 2010. Transient analysis to design buffer capacity in dairy filling and packing production lines. Journal of Food Engineering, 98(1), 1-12.

Wang, S., Xue, X., Yan, C., 2014. Building power demand response methods toward smart grid. HVAC\&R Research, 20(6), 665-687. 
Wang, Y., Li, L., 2012. Heterogeneous redundancy allocation for series-parallel multi-state systems using hybrid particle swarm optimization and local search. IEEE Transactions on Systems Man and Cybernetics Part A: Systems and Humans, 42(2), 464-474.

Wang, Y., Li, L., 2013. Time-of-use based electricity demand response for sustainable manufacturing systems. Energy, 63, 233-244.

Wang, Y., Li, L., 2014. Time-of-use based electricity cost of manufacturing systems: Modeling and monotonicity analysis. International Journal of Production Economics, 156, 246-259.

Wang, Y., Li, L., 2015. A novel modeling method for both steady-state and transient analyses of typical production systems. IEEE Transactions on Systems, Man, and Cybernetics: Systems, 45(1), 97108.

Weinert, N., Chiotellis, S., Seliger, G., 2011. Methodology for planning and operating energy-efficient production systems. CIRP Annals - Manufacturing Technology, 60(1), 41-44.

Wernau, J., 2014. ComEd customers face big price increases. Retrieved Oct. 23, 2014, from http://articles.chicagotribune.com/2014-05-07/business/chi-comed-price-increases20140507_1_comed-david-kolata-power-customers.

West Penn Power Company, 2012. West Penn Power Company tariff. Retrieved November 1, 2014, from http://www.firstenergycorp.com/content/dam/customer/Customer\%20Choice/Files/PA/tariffs/WP P\%20Complete\%20Tariff\%20No\%2039\%20with\%20Supp\%20212.pdf.

Yang, W.-A., Guo, Y., Liao, W., 2011. Multi-objective optimization of multi-pass face milling using particle swarm intelligence. International Journal of Advanced Manufacturing Technology, 56(58), 429-443. 
Table 1. Typical pricing profiles in New York, USA

(a). Flat-rate

\begin{tabular}{|c|c|c|c|}
\hline Season & Time of day & $\begin{array}{c}\text { Energy rate } \\
(\$ / \mathbf{k W h})\end{array}$ & Other charges (\$/month) \\
\hline Summer(Jun-Sep) & All time & 0.18015 & \multirow[b]{2}{*}{33.15} \\
\hline $\begin{array}{c}\text { Winter } \\
\text { (Oct-May) }\end{array}$ & All time & 0.16052 & \\
\hline
\end{tabular}

(b). TOU rate

\begin{tabular}{|c|c|c|c|c|}
\hline \multirow{2}{*}{ Season } & Time of day & $\begin{array}{c}\text { Energy } \\
\text { rate } \\
\mathbf{( \$ / k W h )}\end{array}$ & $\begin{array}{c}\text { Demand } \\
\text { rate } \\
\mathbf{( \$ / k W )}\end{array}$ & \multirow{2}{*}{$\begin{array}{c}\text { Other charges } \\
\mathbf{( \$ / m o n t h )}\end{array}$} \\
\hline \multirow{2}{*}{$\begin{array}{c}\text { Summer(Jun } \\
\text {-Sep) }\end{array}$} & $7 p m-1 p m$ (Off-peak) & 0.10551 & 0 & \multirow{2}{*}{51.32} \\
\cline { 2 - 4 } $\begin{array}{c}\text { Winter } \\
\text { (Oct-May) }\end{array}$ & $\begin{array}{c}\text { 9pm-10am (Off- } \\
\text { peak) }\end{array}$ & 0.18815 & 19.41 & \multirow{2}{*}{0} \\
\cline { 2 - 4 } & $10 a m-9 p m$ (On-peak) & 0.13065 & 8.38 & \\
\hline
\end{tabular}


Table 2. Typical TOU and CPP pricing profiles in California, USA (a). Base TOU rate (SDGE AL-TOU EECC)

\begin{tabular}{|c|c|c|c|c|}
\hline Season & Time of day & $\begin{array}{l}\text { Energy } \\
\text { rate } \\
\text { (\$/kWh) }\end{array}$ & $\begin{array}{c}\text { Demand } \\
\text { rate } \\
(\$ / \mathbf{k W}) \\
\end{array}$ & $\begin{array}{l}\text { Other charges } \\
\text { (\$/month) }\end{array}$ \\
\hline \multirow{3}{*}{$\begin{array}{c}\text { Summer(May } \\
\text {-Oct) }\end{array}$} & $\begin{array}{c}\text { 10pm-6am (Off- } \\
\text { peak) }\end{array}$ & 0.08777 & 20.77 & \multirow{6}{*}{87.83} \\
\hline & $\begin{array}{c}\text { 6am-11am; } \\
\text { 6pm-10pm (Mid- } \\
\text { peak) }\end{array}$ & 0.11807 & 20.77 & \\
\hline & 11am-6pm (On-peak) & 0.12849 & $\underline{41.87}$ & \\
\hline \multirow{3}{*}{$\begin{array}{c}\text { Winter } \\
\text { (Nov-Apr) }\end{array}$} & $\begin{array}{c}\text { 10pm-6am (Off- } \\
\text { peak) }\end{array}$ & 0.07896 & 20.77 & \\
\hline & $\begin{array}{c}\text { 6am-5pm; } \\
\text { 8pm-10pm (Mid- } \\
\text { peak) }\end{array}$ & 0.10184 & 20.77 & \\
\hline & 5pm-8pm (On-peak) & 0.11845 & 27.91 & \\
\hline
\end{tabular}

(b). CPP rate and credit during non-event days (SDGE AL-TOU EECC-CPP-D)

\begin{tabular}{|c|c|c|c|c|}
\hline Season & Time of day & $\begin{array}{l}\text { Energy } \\
\text { rate } \\
(\$ / \mathbf{k W h})\end{array}$ & $\begin{array}{c}\text { Demand } \\
\text { rate } \\
(\$ / \mathbf{k W})\end{array}$ & $\begin{array}{l}\text { Other charges } \\
\text { (\$/month) }\end{array}$ \\
\hline \multirow{3}{*}{$\begin{array}{c}\text { Summer(May } \\
\text {-Oct) }\end{array}$} & $\begin{array}{l}\text { 10pm-6am (Off- } \\
\text { peak) }\end{array}$ & 0.08777 & 20.77 & \multirow{6}{*}{87.83} \\
\hline & $\begin{array}{c}\text { 6am-11am; } \\
\text { 6pm-10pm (Mid- } \\
\text { peak) }\end{array}$ & 0.11807 & 20.77 & \\
\hline & 11am-6pm (On-peak) & 0.12849 & 41.87-11.30 & \\
\hline \multirow{3}{*}{$\begin{array}{c}\text { Winter } \\
\text { (Nov-Apr) }\end{array}$} & $\begin{array}{c}\begin{array}{c}\text { 10pm-6am (Off- } \\
\text { peak) }\end{array} \\
\end{array}$ & 0.07896 & 20.77 & \\
\hline & $\begin{array}{c}\text { 6am-5pm; } \\
\text { 8pm-10pm (Mid- } \\
\text { peak) }\end{array}$ & 0.10184 & 20.77 & \\
\hline & 5pm-8pm (On-peak) & 0.11845 & 27.91 & \\
\hline
\end{tabular}

(c). CPP adder during event days (SDGE AL-TOU-CPP-D)

\begin{tabular}{|c|c|c|c|c|}
\hline Season & Time of day & $\begin{array}{l}\text { Energy rate } \\
(\$ / \mathbf{k W h})\end{array}$ & $\begin{array}{c}\text { Demand rate } \\
(\$ / \mathbf{k W})\end{array}$ & $\begin{array}{c}\text { Other charges } \\
\text { (\$/month) }\end{array}$ \\
\hline \multirow{3}{*}{$\begin{array}{l}\text { Summe } \\
\text { r(May- } \\
\text { Oct) }\end{array}$} & 10pm-6am (Off-peak) & 0.08777 & 20.77 & \multirow{5}{*}{87.83} \\
\hline & $\begin{array}{l}\text { 6am-11am; } \\
\text { 6pm-10pm (Mid- } \\
\text { peak) }\end{array}$ & 0.11807 & 20.77 & \\
\hline & 11am-6pm (On-peak) & $\underline{0.12849+1.39243}$ & $\underline{41.87-11.30}$ & \\
\hline \multirow{2}{*}{$\begin{array}{l}\text { Winter } \\
\text { (Nov- } \\
\text { Apr) }\end{array}$} & 10pm-6am (Off-peak) & 0.07896 & 20.77 & \\
\hline & $\begin{array}{c}\text { 6am-5pm; } \\
\text { 8pm-10pm (Mid- }\end{array}$ & 0.10184 & 20.77 & \\
\hline
\end{tabular}




\begin{tabular}{|c|c|c|c|c|}
\hline & peak) & & \multirow{2}{*}{} \\
\cline { 2 - 3 } & $5 \mathrm{pm}-8 \mathrm{pm}$ (On-peak) & 0.11845 & 27.91 & \\
\hline
\end{tabular}




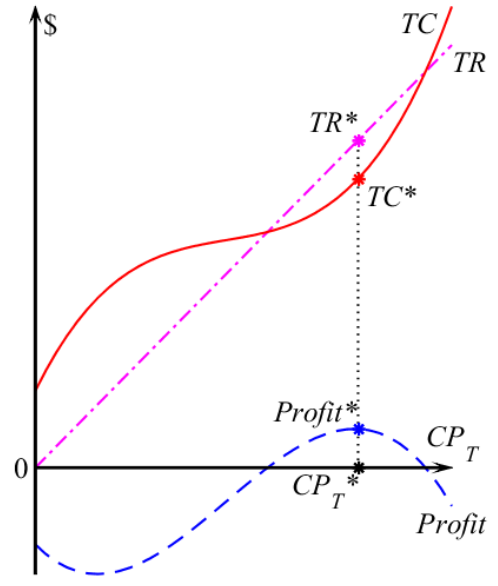

(a)Solid: Total cost curve; Dot-Dashed: Total revenue curve; Dashed: Profit curve

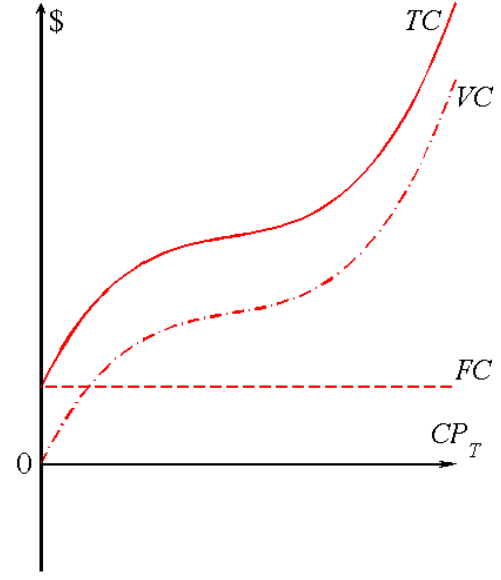

(b) Solid: Total cost curve; Dot-Dashed: Variable cost curve; Dashed: Fixed cost curve

Fig. 1. Decomposition of the profit (a) and the total cost (b) 


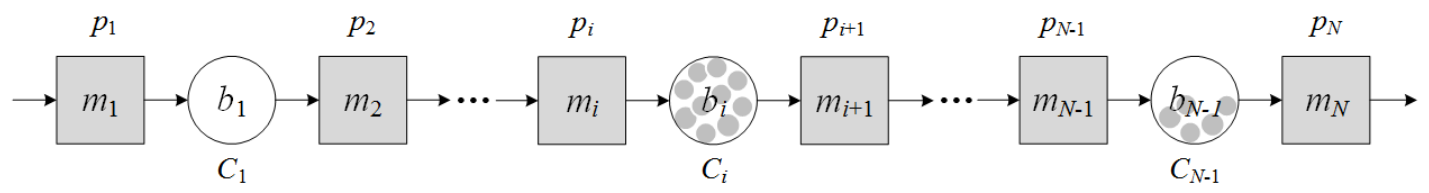

Fig. 2. Diagram of a typical manufacturing system 

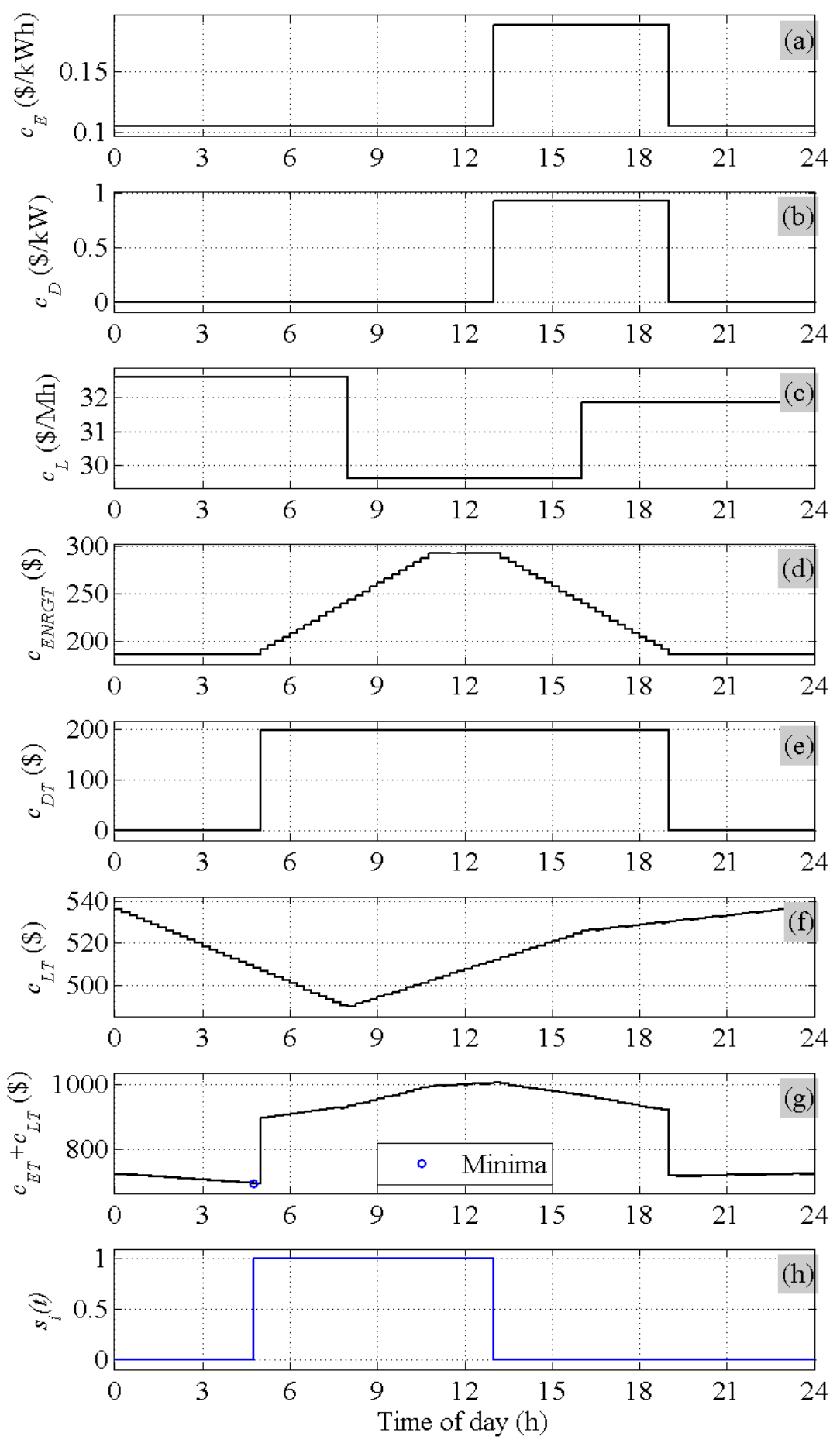

Fig. 3. Results of Example 1 

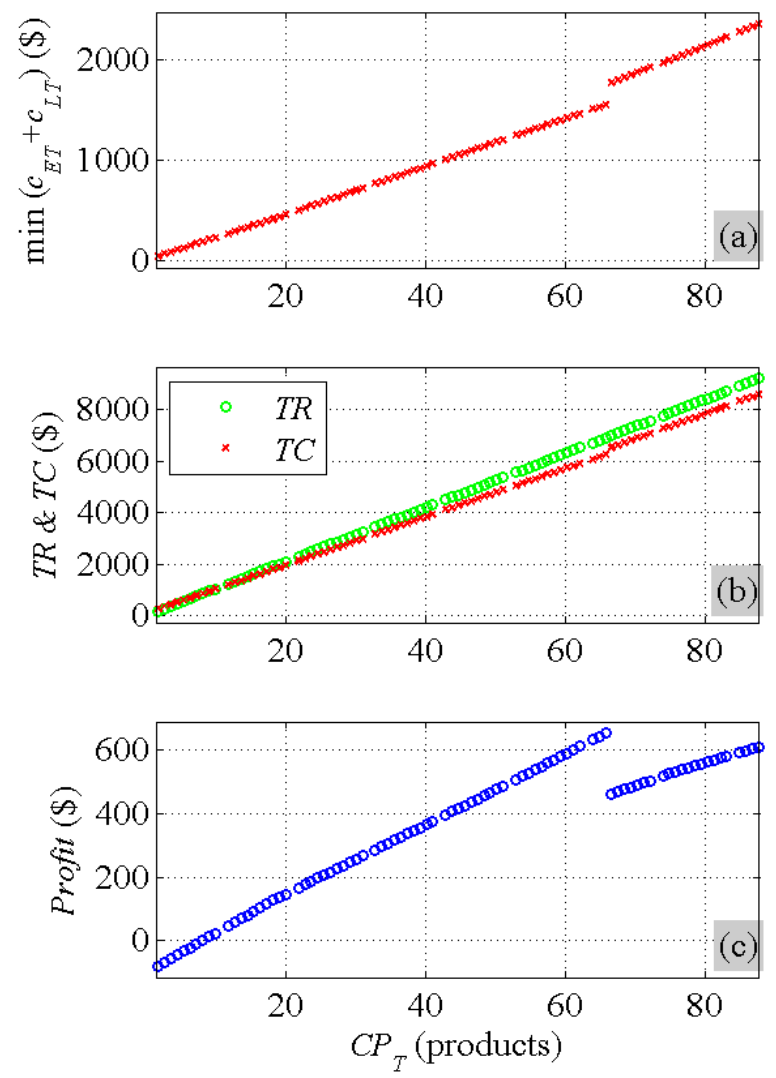

Fig. 4. Results of Example 3. 


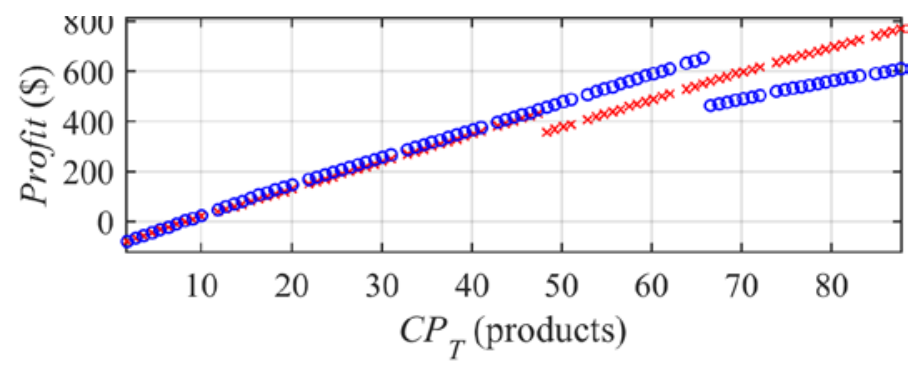

$\times$ Winter $w=2 C_{i}=3 p_{i}=0.95$ Steady

○ Summer $w=2 C_{i}=3 p_{i}=0.95$ Steady

(a)

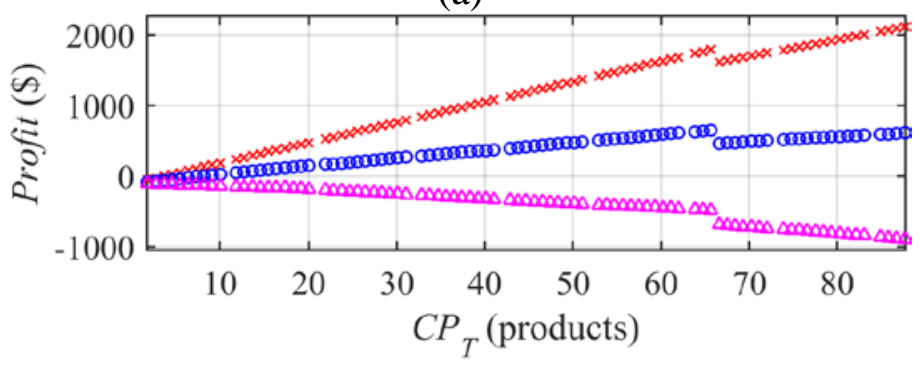

× Summer $w=0 \quad C_{i}=3 p_{i}=0.95$ Steady

○ Summer $w=2 C_{i}=3 p_{i}=0.95$ Steady

$\triangle$ Summer $w=4 C_{i}=3 p_{i}=0.95$ Steady

(b)

Fig. 5. Effects of the TOU seasons (a) and the number of workers (b) 


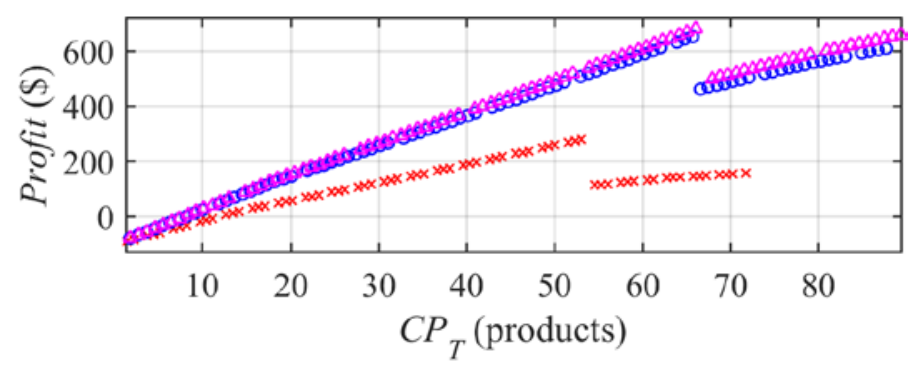

Summer $w=2 \quad C_{i}=1 p_{i}=0.95$ Steady

○ Summer $w=2 C_{i}=3 p_{i}=0.95$ Steady

$\triangle$ Summer $w=2 \quad C_{i}=5 p_{i}=0.95$ Steady

(a)

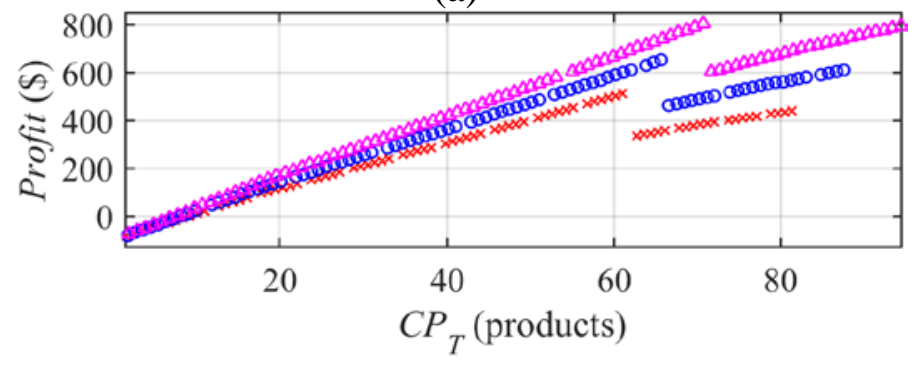

$\times$ Summer $w=2 C_{i}=3 p_{i}=0.91$ Steady
$\circ$ Summer $w=2 C_{i}=3 p_{i}=0.95$ Steady
$\triangle \quad$ Summer $w=2 \quad C_{i}=3 p_{i}=0.99$ Steady

(b)

Fig. 6. Effects of the buffer capacity (a) and the machine reliability (b) 


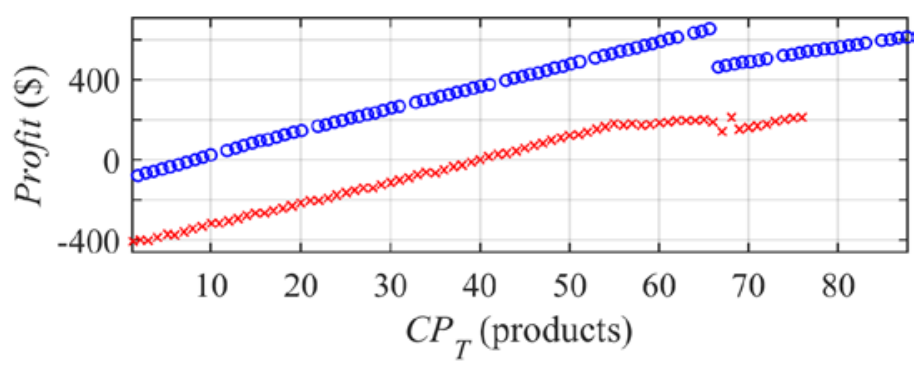

(a)

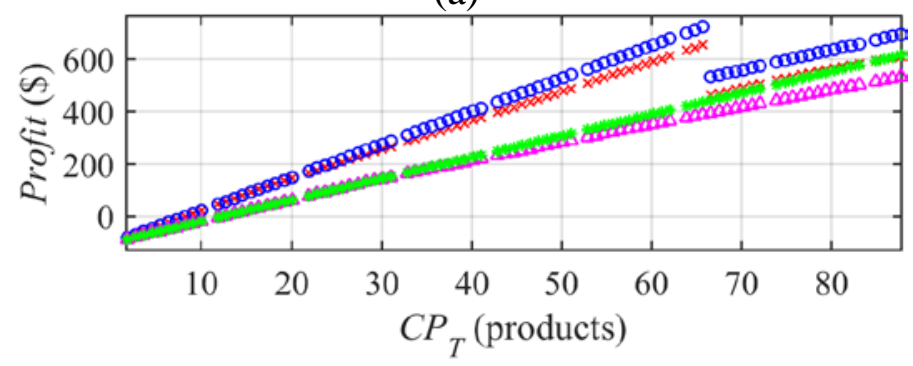

$\times \quad$ Summer $w=2 C_{i}=3 p_{i}=0.95$ Steady
$\circ \quad$ Summer $w=2 C_{i}=3 p_{i}=0.95$ Steady VaryElectric
$\triangle \quad$ Summer $w=2 C_{i}=3 p_{i}=0.95$ Steady VaryWage
$* \quad$ Summer $w=2 C_{i}=3 p_{i}=0.95$ Steady BothFlat

(b)

Fig. 7. Effects of the initial condition (a) and the time-varying pricing (b) 


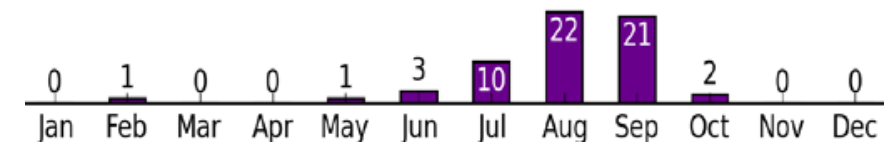

(a)

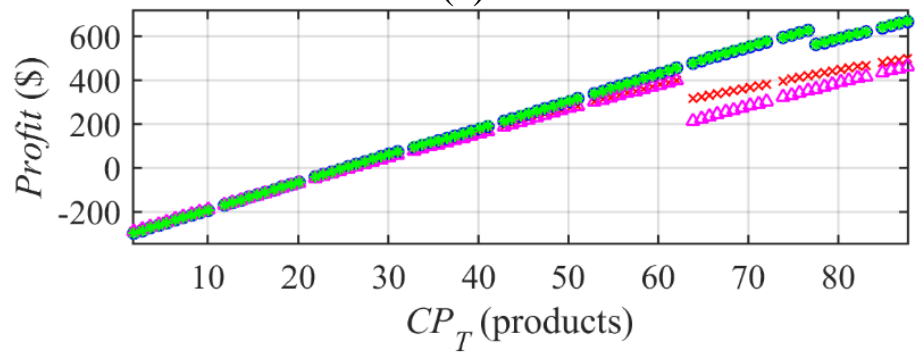

$\begin{array}{ll}\times & \text { CPPSummer } w=2 C_{i}=3 p_{i}=0.95 \text { Steady } \\ \circ & \text { CPPWinter } w=2 C_{i}=3 p_{i}=0.95 \text { Steady } \\ \triangle & \text { TOUSummer } w=2 C_{i}=3 p_{i}=0.95 \text { Steady } \\ * & \text { TOUWinter } w=2 C_{i}=3 p_{i}=0.95 \text { Steady }\end{array}$

(b)

Fig. 8. Historical CPP events in SDGE by month (a) and Effects of the TOU vs. CPP (b) 